\title{
Article \\ Application of Combined Analyses of Stable Isotopes and Stomach Contents for Understanding Ontogenetic Niche Shifts in Silver Croaker (Pennahia argentata)
}

\author{
Bohyung Choi ${ }^{1}$, Won-Seok Kim ${ }^{2}$, Chang Woo Ji ${ }^{1}$, Min-Seob Kim ${ }^{3}{ }^{1}$ and Ihn-Sil Kwak ${ }^{1,2, *}$ \\ 1 Fisheries Science Institute, Chonnam National University, Yeosu 59626, Korea; \\ chboh1982@chonnam.ac.kr (B.C.); jichangwoo@gmail.com (C.W.J.) \\ 2 Department of Ocean Integrated Science, Chonnam National University, Yeosu 59626, Korea; \\ csktjr123@gmail.com \\ 3 Department of Fundamental Environment Research, Environmental Measurement and Analysis Center, \\ National Institute of Environmental Research, Incheon 22689, Korea; candyfrog77@gmail.com \\ * Correspondence: iskwak@chonnam.ac.kr; Tel.: +82-10-3575-5449
}

check for updates

Citation: Choi, B.; Kim, W.-S.; Ji, C.W.; Kim, M.-S.; Kwak, I.-S.

Application of Combined Analyses of Stable Isotopes and Stomach Contents for Understanding Ontogenetic Niche Shifts in Silver Croaker (Pennahia argentata). Int. J. Environ. Res. Public Health 2021, 18, 4073. https:// doi.org/10.3390/ijerph18084073

Academic Editor: Paul B. Tchounwou

Received: 2 March 2021

Accepted: 8 April 2021

Published: 13 April 2021

Publisher's Note: MDPI stays neutral with regard to jurisdictional claims in published maps and institutional affiliations.

Copyright: (C) 2021 by the authors. Licensee MDPI, Basel, Switzerland. This article is an open access article distributed under the terms and conditions of the Creative Commons Attribution (CC BY) license (https:// creativecommons.org/licenses/by/ $4.0 /)$.

\begin{abstract}
Stable isotope analysis (SIA) and stomach content analysis (SCA) were conducted to understand ontogenetic niche shifts in silver croaker Pennahia argentata inhabiting the southern coastal waters of the Korean peninsula. Sampled P. argentata were classified into three groups based on their total length (TL; 60-80 mm TL, 80-120 mm TL, and 120-210 mm TL). Carbon isotope $\left(\delta^{13} \mathrm{C}\right)$ ratios were distinguishable, whereas nitrogen isotope $\left(\delta^{15} \mathrm{~N}\right)$ ratios were not significantly different among size classes, and Standard Ellipse Area (SEA), estimated by $\delta^{13} \mathrm{C}$ and $\delta^{15} \mathrm{~N}$, was expanded with increasing TL from $0.2 \%^{2}\left(60-80 \mathrm{~mm}\right.$ TL) to $2.0 \%^{2}(120-210 \mathrm{~mm}$ TL). SCA results showed variable contribution of dietary items to each size class. In particular, higher dietary contribution of Polychaeta to P. argentata of $80-120 \mathrm{~mm}$ TL than $120-210 \mathrm{~mm}$ TL mirrored variation in $\delta^{13} \mathrm{C}$ values of $P$. argentata in those size classes. Based on the combined analyses involving SIA and SCA, we concluded that $P$. argentata underwent ontogenetic niche shifts, particularly dietary shifts, with growth stages. Ontogenetic niche shifting is a representative survival strategy in fish, and, therefore, represents essential information for managing fisheries. The present study demonstrated applicability of combined SIA and SCA analyses, not only for dietary resource tracing, but also for ecological niche studies.
\end{abstract}

Keywords: stable isotope analysis; stomach content analysis; ontogenetic niche shift; Pennahia argentata

\section{Introduction}

The ecological niche, a fundamental concept in ecology, involves a variety of issues such as dietary resources, habitat information, and interactions among organisms [1]. Therefore, understanding the niche of organisms in an ecosystem has been considered as one of the most important tasks in ecology for several decades. One frequently applied tool for such study is stable isotope analysis (SIA), particularly using carbon and nitrogen isotope ratios. The minor difference in carbon isotope $\left(\delta^{13} \mathrm{C}\right)$ ratio between dietary resources and consumers provides diet information and the geographical habitat of consumers, whereas stepwise nitrogen isotopic enrichment along the food chain reflects trophic information regarding organisms [2,3]. Consequently, dual plots based on these two isotope ratios are used to illustrate food web structures of an ecosystem, with synthetically view of both dietary resources and trophic information, and, thus, the width of a polygon drawn by $\delta^{13} \mathrm{C}$ and $\delta^{15} \mathrm{~N}$ values for a species is used as an ecological niche space $(\delta$-space) $[4,5]$. The comparison of $\delta$-space within and among species is used to understand ecological niches and interactions among organisms in an ecosystem [6-8]. However, complex information involving both $\delta^{13} \mathrm{C}$ and $\delta^{15} \mathrm{~N}$ sometimes hinders us in identifying the key-factors driving 
ecological niche variation of organisms. For example, differences in $\delta^{13} \mathrm{C}$ values among consumers are generally derived from different dietary resources, but also indicate diverse habitats of organisms consuming homogeneous dietary resources $[9,10]$. The $\delta^{15} \mathrm{~N}$ value of consumers generally indicates trophic hierarchy, but also can be varied to reflect that of basal organisms in a food web $[11,12]$. Therefore, variation in the $\delta$-space implies diverse ecological interactions (i.e., competition or segregation involving habitat, diet, and different trophic status) and may lead to confusion in ecological interpretation.

Stomach content analysis (SCA) has traditionally been applied to identify consumer dietary items due to the provision of fine-resolution information at relatively low cost [13]. Moreover, SCA provides both quantitative and qualitative information concerning dietary items [14]. For instance, the weight of stomach contents provides quantitative information, and occurrence frequency indicates diet preference of a consumer, attributing quality of diet items for the consumer. However, only obtaining snapshot information and the requirement for enormous sample sizes are always regarded as inherent limitations to this approach $[15,16]$. Thus, recently, the combination of SCA and SIA offers a reinforcement tool for food web studies due to complementation of weaknesses inherent in each individual approach $[13,15,17]$. These combined analyses are also potentially applicable for niche identification studies. For instance, variations in $\delta$-space involving both dietary and habitat changes can be more simply interpreted with information regarding dietary preferences obtained from SCA.

Silver croaker Pennahia argentata is a representative demersal fish distributed from east of Japan to the Indo Pacific, including the East China Sea and the Yellow Sea [18]. This species is regarded as commercially important, but catch limits have been gradually decreasing over recent years [19-21]. Despite its commercial importance, feeding strategies and dietary components of this species have rarely been reported and, moreover, information regarding ontogenetic diet shifting in this species is scarce. Dietary variability within a species has diverse purposes, such as nutritional requirements, morphological adaptation, and as a survival strategy in habitat competition [22]. Therefore, knowledge surrounding ontogenetic niche variation in a commercially important fish will be helpful in terms of managing marine resources production.

The purpose of the present study was to determine ontogenetic niche variation and diet changes in P. argentata caught in Gwangyang Bay, South Korea. Carbon and nitrogen stable isotope analysis was applied to determine niche widths for different groups of $P$. argentata, classified by total length, and their dietary information was obtained by SCA. This combined approach was used to explain the importance of dietary variations in determining $P$. argentata niche space.

\section{Materials and Methods}

\subsection{Sampling and Study Sites}

Gwanyang Bay is a semi-closed bay, and is connected with the Seomjin River. This bay is well known to have a high diversity of fish species due to the development of an estuary in the upper areas. Gwangyang Bay is geographically separated into four groups (estuary, main channel, outer bay, and inner bay), based on chemical and physical properties [23]. Sample collection was performed in September 2018 at three sites (St. 1, St. 2, and St. 3) in the main channel, which is characterized as exhibiting low metal concentrations, and at one site (St. 4) in the outer bay with high salinity (Figure 1). A small bottom-trawl net (length $8 \mathrm{~m}$, width $8 \mathrm{~m}$, mesh wing and body $3 \mathrm{~cm}$, mesh liner $1 \mathrm{~cm}$ ) was towed for $10 \mathrm{~min}$ at 1 2 knots at each sampling site. Seventy-eight samples were collected and immediately kept at $-80{ }^{\circ} \mathrm{C}$ until delivery to a laboratory. Total length (TL) of each specimen was measured and classified into three groups based on their TL (60-80 mm TL, 26 individuals; 80-120 mm TL, 25 individuals; $120-210 \mathrm{~mm}$ TL, 27 individuals). The gut of each specimen was dissected and then preserved in $70 \%$ ethanol before examination. Forty-one samples were randomly selected, and dorsal muscle was dissected for SIA. 


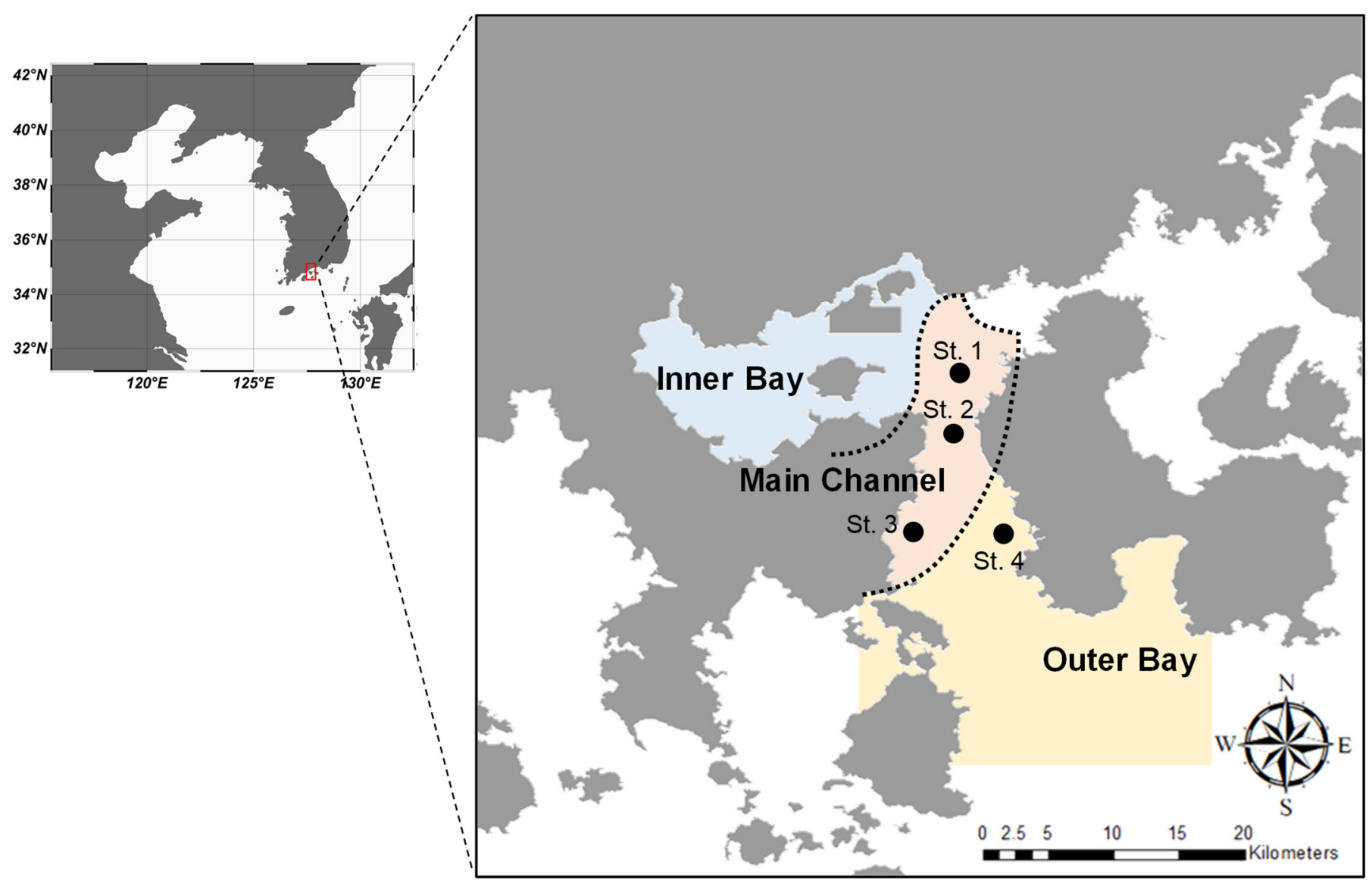

Figure 1. Map illustrating sampling sites in Gwangyang Bay. The boundaries in the bay are as defined by Kim et al. [23] 2019, based on physical and chemical properties.

\subsection{Stomach Content Analysis and Stable Isotope Analysis}

Contents of the stomach were identified under a dissecting microscope (Olympus, SZX9, Tokyo, Japan) at a magnification of 20 to $100 \times$, and classified into class levels. Because of diverse sizes, the unidentified contents were pooled and weighed together. Each identified content was weighed to the nearest $0.01 \mathrm{mg}$ after removing excess moisture. The weight and frequency of unidentified contents were excluded in the estimation of relative abundance of diet items.

The extracted dorsal muscles were homogenized with a mortar and pestle after freezedrying, and approximately $1 \mathrm{mg}$ of each sample was sealed in a tin cap for carbon (C) and nitrogen (N) stable isotope analysis. Stable isotope analyses were performed using an isotope ratio mass spectrometer linked with an elemental analyzer (EA-IRMS, Isoprime, Manchester, UK). Samples for C stable isotope analysis generally required lipid removal; however, this process was omitted due to low and similar lipid contents in the samples [24]. The measured stable isotope ratios are expressed as ' $\delta$ ' values by following Equation (1).

$$
\begin{gathered}
\delta^{13} \mathrm{C} \text { or } \delta^{15} \mathrm{~N}=\left[\left(\mathrm{R}_{\text {sample }} / \mathrm{R}_{\text {standard }}\right)-1\right] \times 1000(\%), \\
\left(\mathrm{R}={ }^{13} \mathrm{C} /{ }^{12} \mathrm{C} \text { for carbon isotope, and }{ }^{15} \mathrm{~N} /{ }^{14} \mathrm{~N} \text { for nitrogen isotope, respectively }\right)
\end{gathered}
$$

where, vPDB (Vienna PeeDee Belemnite, International Atomic Energy Agency (IAEA)) and atmospheric $\mathrm{N}_{2}$ gas were used as standards for $\delta^{13} \mathrm{C}$ and $\delta^{15} \mathrm{~N}$, respectively. $\mathrm{CH}-3$ $\left(\delta^{13} \mathrm{C}=-24.72 \pm 0.1 \%\right.$ ) and $\mathrm{N}-1\left(\delta^{15} \mathrm{~N}=0.4 \pm 0.1 \%\right.$ o $)$ provided by the IAEA were analyzed after every five sample runs to check for analytical errors $(1 \sigma= \pm 0.1 \%$ o for $\delta 13 \mathrm{C}$ and $1 \sigma= \pm 0.2 \%$ for $\delta 15 \mathrm{~N}$, respectively). 


\subsection{Statistical Analysis}

Significance of TL, $\delta^{13} \mathrm{C}$, and $\delta^{15} \mathrm{~N}$ of P. argentata across sampling zones defined by Kim et al. [23] was evaluated by one-way analysis of variance (ANOVA), and differences in $\delta^{13} \mathrm{C}$, and $\delta^{15} \mathrm{~N}$ among sizes classified for P. argentata were confirmed by two-way ANOVA. Tukey and Duncan's multiple range methods were applied for post-hoc test using $\mathrm{R}$ (ver. 3.6.1).

Evaluation of isotopic niches for each TL-classified P. argentata was conducted by Stable Isotope Bayesian Ellipses in R (R package SIBER, Jackson et al. [5]), based on the $\delta^{13} \mathrm{C}$, and $\delta^{15} \mathrm{~N}$ values. The $\delta$-space, Standard Ellipse Area (SEA), and overlap proportions were obtained using SIBER.

\section{Results}

\subsection{P. argentata Spatial Variation}

All $P$. argentata samples analyzed in this study demonstrated large ranges of $\delta^{13} \mathrm{C}$ $\left(-16.6 \%\right.$ to $-13.1 \%$ ) and $\delta^{15} \mathrm{~N}\left(11.8 \%\right.$ to $15.5 \%$ ). However, both $\delta^{13} \mathrm{C}$ and $\delta^{15} \mathrm{~N}$ of $P$. argentata sampled in the main channel and outer bay were not significantly different $(p>0.5)$ (Table 1). Therefore, isotopic niche evaluation in the present study did not involve consideration of spatial variation in isotope ratios of $P$. argentata.

Table 1. Spatial variation in carbon and nitrogen isotope ratios in P. argentata sampled at Gwangyang Bay. Main channel (St. 1, St. 2, St. 3 in Figure 1) and outer bay (St. 4) were separated by physical and chemical properties, as documented by Kim et al. (2019).

\begin{tabular}{ccccc}
\hline & Site & (n) & Avg. \pm S.D. & p-Value ${ }^{\mathbf{1}}$ \\
\hline \multirow{2}{*}{$\delta^{13} \mathrm{C}(\%)$} & main channel & 25 & $-14.5 \pm 1.1$ & \multirow{2}{*}{0.2952} \\
& outer bay & 16 & $-14.8 \pm 0.7$ & \\
\multirow{2}{*}{$\delta^{15} \mathrm{~N}(\%$ ) $)$} & main channel & 25 & $14.0 \pm 0.7$ & 0.520 \\
& outer bay & 16 & $14.1 \pm 0.5$ & \multirow{2}{*}{0.4639} \\
\multirow{2}{*}{ Total Length (TL, mm) } & main channel & 55 & $112.7 \pm 46.0$ & \\
& outer bay & 22 & $122.9 \pm 57.6$ & \\
\hline
\end{tabular}

${ }^{1}$ Statistical significance was evaluated by one-way ANOVA.

\subsection{Stable Isotope Ratios of Size-Classified P. argentata}

$\delta^{13} \mathrm{C}$ values in P. argentata ranged from $-15.6 \%$ to $-13.7 \%$ in the $60-80 \mathrm{~mm}$ TL group, from $-16.6 \%$ to $-13.5 \%$ in the $80-120 \mathrm{~mm}$ TL group, and from $-16.6 \%$ to $-13.6 \%$ in the $120-210 \mathrm{~mm}$ TL cohort (Figure 2a). $\delta^{13} \mathrm{C}$ values in the $60-80 \mathrm{~mm}$ TL and $80-120 \mathrm{~mm}$ TL groups were not statistically different, whereas those of the 120-210 $\mathrm{mm}$ TL group were significantly different compared to the other groups $(p<0.05) . \delta^{15} \mathrm{~N}$ values in P. argentata ranged from $11.8 \%$ to $15.5 \%$, with no statistical differences among size-fractionated groups (Figure 2b). However, the range of $\delta^{15} \mathrm{~N}$ values was widest in $120-210 \mathrm{~mm}$ TL fish $(11.8 \%$ to $15.5 \%$ ) and narrowest in the $60-80 \mathrm{~mm}$ TL group $(13.4 \%$ o to $15.2 \%$ ).

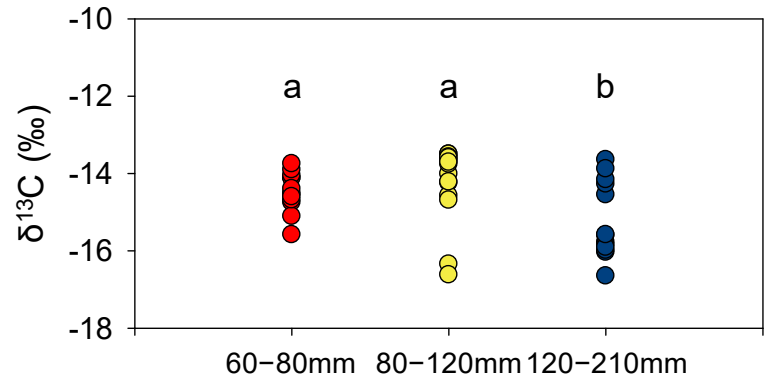

(a)

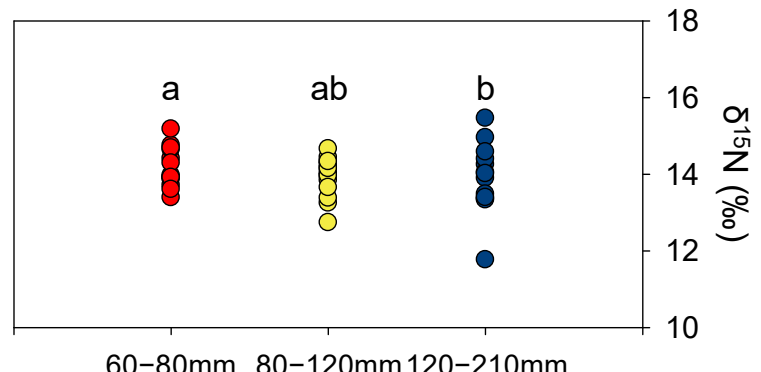

(b)

Figure 2. $\delta^{13} \mathrm{C}(\mathbf{a})$ and $\delta^{15} \mathrm{~N}(\mathbf{b})$ values of $P$. argentata classified by their TL (mm). The letters indicate significant differences among size classes $\left(p<0.05\right.$ for $\delta^{13} \mathrm{C}$, and $p>0.5$ for $\left.\delta^{15} \mathrm{~N}\right)$. 
The $P$. argentata group comprising $80-120 \mathrm{~mm}$ was positioned relatively higher in terms of $\delta^{13} \mathrm{C}$ values in $\delta$-space, whereas the 120-210 mm TL group showed greater depleted of their carbon isotopes (Figure 3a). The distinct $\delta$-space in the 120-210 $\mathrm{mm}$ TL cohort resulted in little overlap with the $60-80 \mathrm{~mm}$ TL group (13.6\%), while the overlapping $\delta$-space between the $60-80 \mathrm{~mm}$ TL and $80-120 \mathrm{~mm}$ groups was $18.6 \%$. SEA, which indicates niche width, was the smallest in the $60-80 \mathrm{~mm}$ TL group $\left(0.4 \%{ }^{2}\right)$, and increased with their TL $\left(1.1 \%^{2}\right.$ for $80-120 \mathrm{~mm}$ TL, and $2.0 \%{ }^{2}$ for the $120-210 \mathrm{~mm}$ TL specimens, respectively), indicating expansion of niche width in this species accompanied by their growth (Figure 3b).
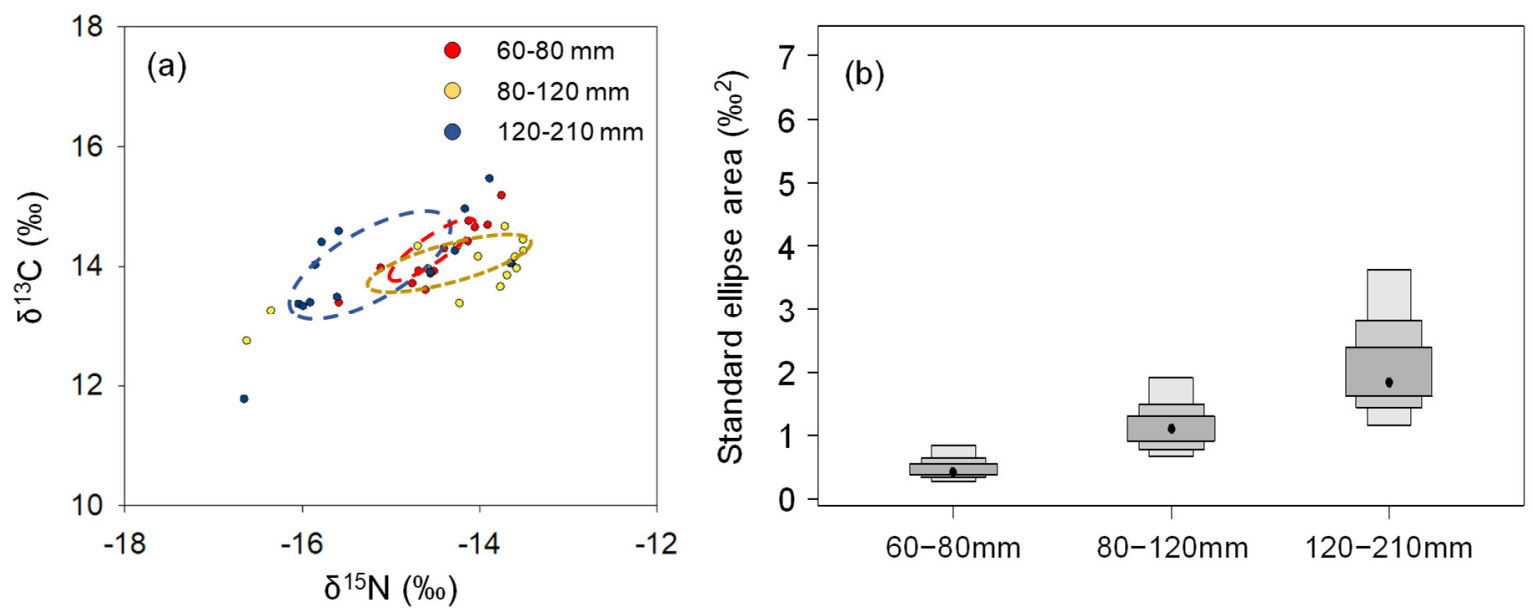

Figure 3. Isotopic niche of $P$. argentata classified by total length. (a) shows " $\delta$-space" illustrated by dual plots of $\delta^{13} \mathrm{C}$ and $\delta^{15} \mathrm{~N}$ values, and (b) indicates estimated standard ellipse area by SIBER for each class.

\subsection{Stomach Contents of Size-Classified P. argentata}

Stomach contents were examined in 50 specimens from 78 P. argentata samples; the remaining specimens ( 28 individuals) had empty guts. Among the size groups, specimens with empty guts were frequent in the $60-80 \mathrm{~mm}$ TL, while all gut samples had dietary contents in specimens of the 120-210 mm TL (Table 2). The amounts of unidentified contents followed size groups, with the highest in the $120-210 \mathrm{~mm}$ TL class, and the smallest in the 80-120 mm TL group. However, proportions of unidentified contents were higher in the $60-80 \mathrm{~mm}$ TL than in other size groups, and similar in the $80-120 \mathrm{~mm}$ TL and 120-210 mm TL specimens.

Table 2. Information regarding empty and unidentified stomach contents in P. argentata classified by total length.

\begin{tabular}{cccc}
\hline Size Classes of $\boldsymbol{P}$. argentata & $\mathbf{6 0 - 8 0 ~} \mathbf{~ m}$ & $\mathbf{8 0 - 1 2 0 ~} \mathbf{m m}$ & $\mathbf{1 2 0 - 2 1 0 ~} \mathbf{m m}$ \\
\hline No. of examined specimens (n) & 26 & 25 & 27 \\
No. of empty stomachs (n) & 19 & 9 & 0 \\
\% of empty stomachs (\%) & 73.1 & 36 & 0 \\
Total Weight of stomach contents (g) & 0.3 & 5.5 & 31.6 \\
Weight of unidentified contents (g) & 0.2 & 0.8 & 8.9 \\
\% of unidentified contents (\%) & 62.5 & 14.2 & 28.1 \\
\hline
\end{tabular}

Although relative abundances were different, both total weight and frequency of diet contents significantly increased with fish size, indicating greater dietary consumption in greater TL specimens (Figure 4a,b). Indeed, large numbers of specimens with empty stomachs included P. argentata in the 60-80 mm TL group, resulting in simple diet information. 

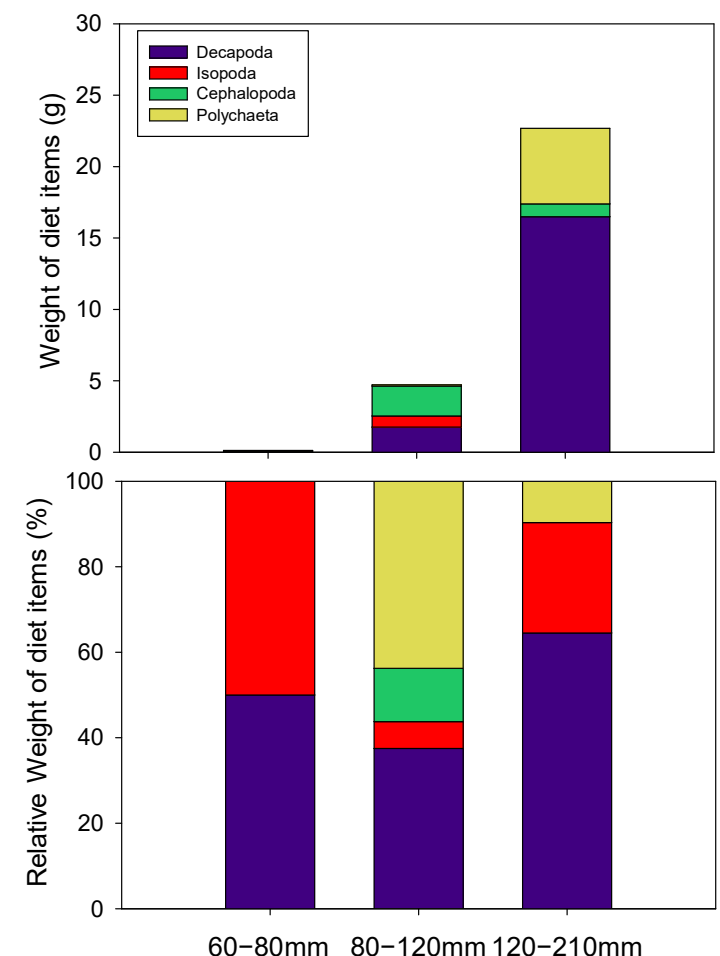

(a)

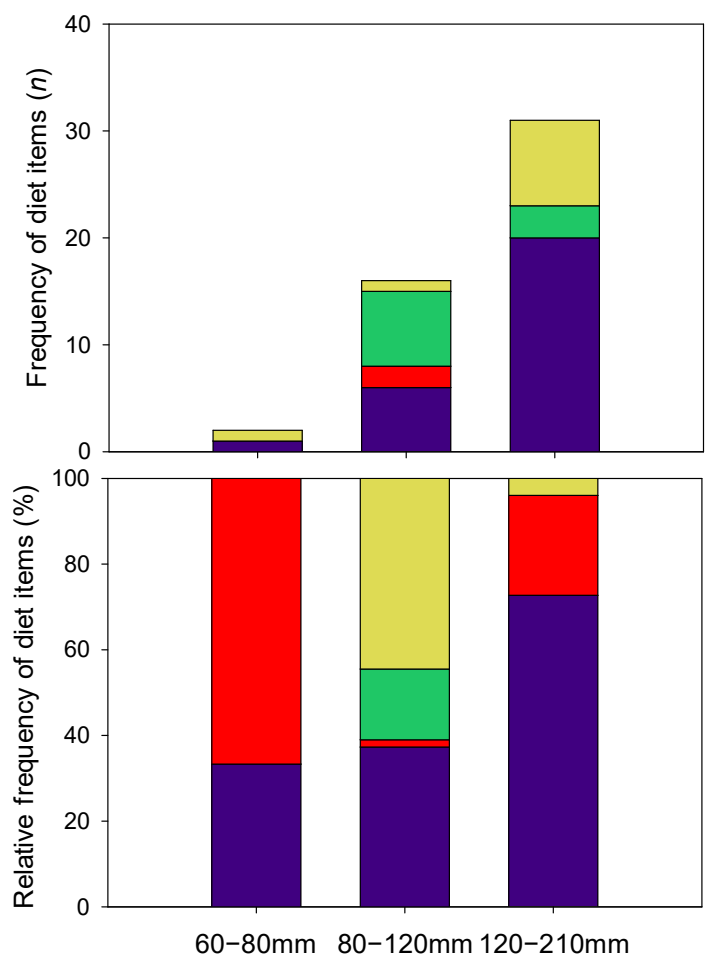

(b)

Figure 4. Stomach contents in each size class of P. argentata. (a) indicates contribution based on total weight and percentage of contents, and (b) indicates dietary contribution based on frequency and percentage of contents.

Dietary items in 60-80 mm TL group consisted only of Crustacea, Decapoda, and Isopoda, at similar frequencies (Figure $4 \mathrm{~b}$ ). However, relative weights of diet items were slightly higher in Isopoda (66.7\%, Figure 4a). Meanwhile, more variable diet items, including Cephalopoda, Polychaeta, and Crustacea (Decapoda and Isopoda), were found in $80-120 \mathrm{~mm}$ TL class. Among the diet items, Polychaeta (43.8\%) and Crustacea (37.5\%) were present at high frequency, while Cephalopoda (12.5\%) and Isopoda (6.25\%) were detected at low frequency. Related abundances in biomass of diet items for 80-120 mm TL fish were also high in Polychaeta (44.5\%) and Crustacea (37.3\%), and low in Cephaloda (16.5\%) and Isopoda (1.7\%). Crustacea were the major dietary component of 120-210 mm TL group, as Decapoda (64.5\%) and $(25.8 \%)$ were detected at high frequency. Relative biomass of each diet item was also high in Decapoda (72.7\%) and Isopoda (23.3\%). Although the present study did not find this diet items in all stomach samples, previous studies have mentioned importance of Teleosts as diet items for P. argentata, [25,26]. In particular, Park et al. [26] demonstrated different diet contribution of teleosts for $P$. argentata between trawl and set net for sampling method. The ppresent study used trawl net for sampling, which may result in the absence of teleost in the stomach of P. argentata.

\section{Discussion}

The $\delta^{13} \mathrm{C}$ values of $P$. argentata analyzed in the present study exhibited a large range, indicating a broad ecological niche in this species. Ecological niche shifts within a species are generally related to their growth, and are, thus, considered as ontogenetic shifts [27,28]. Growth stages in fish are highly correlated with body size. For instance, Ju et al. [29] state that average body lengths in 0 year $P$. argentata samples are close to $80 \mathrm{~mm}$, whereas one-year-old specimens predominantly grew up to approximately $120 \mathrm{~mm}$ TL. Among the $P$. argentata collected in the present study, specimens involving $120-210 \mathrm{~mm}$ TL can be assumed to be older than one year. The $\delta^{13} \mathrm{C}$ values in $120-210 \mathrm{~mm}$ TL specimens were significantly different compared to those in other size groups, with large ranges of 
$\delta^{15} \mathrm{~N}$ values, while $\delta^{13} \mathrm{C}$ and $\delta^{15} \mathrm{~N}$ values were not significantly different in $60-80 \mathrm{~mm}$ and $80-120 \mathrm{~mm}$ TL groups. These distributions in isotope values lead to distinct isotope niche widths among size-classified groups of $P$. argentata. However, broader SEAs in 80 $120 \mathrm{~mm}$ TL fish (1.1) compared to those in 60-80 mm TL animals (0.4) indicated expansion of ecological niche with growth, and large overlap of ellipses in the $60-80 \mathrm{~mm}$ and 80 $120 \mathrm{~mm}$ TL groups explained partial sharing of their habitat and diets. However, distinct $\delta$-space in the 120-210 $\mathrm{mm}$ TL cohort indicated niche separation from other TL classes. Moreover, SEA in this class (2.0) was broader than in other classes, and clearly shows ontogenetic niche expansion with growth in this species. Indeed, distinctly low $\delta^{13} \mathrm{C}$ values $(-15.7 \pm 0.8 \%$ o in fish larger than $170 \mathrm{mmTL}$ seems to offer further clear evidence for ontogenetic niche shifting. Unfortunately, our sample size was insufficient to evaluate niche shift within 120-210 mm TL fish, suggesting further future evaluation for niche shifts in adult $P$. argentata.

Ontogenetic niche shifts have two purposes: reducing predation risk through habitat shifts, and increasing growth through dietary shifts [22,30]. Applications involving SIA in ontogenetic niche studies have previously focused on diet shift scenarios. For instance, Post [22] discussed variable timing of transition from planktivory to piscivory in largemouth bass through nitrogen isotope analysis. Indeed, ontogenetic niche shifts relating to changes in food resources has been well demonstrated by SEA in diverse organisms (i.e., fur seal, Kernaléguen et al. [31]; krill, Zhu et al. [32]; fish, Krumsick and Fisher [33]). However, variable isotopic baselines among habitats are also attributed to wide ranges in isotope ratios. For instance, previous studies have reported higher $\delta^{13} \mathrm{C}$ values in species inhabiting inshore sites than in offshore species $[34,35]$. Therefore, geographical variation in isotope ratios within a given species has also been applied to understand ontogenetic shifts in habitats for diverse animals, including shark [36] and sea turtle [37]. Consequently, ontogenetic variation involving SEA can include shifts in both diet and habitat of a species. However, obtaining simultaneous information for both diet and habitat recorded in the isotope ratios of consumers hinders the ability to validate prevailing causes of niche shifts involving diet and habitat [11]. Thus, although distinct SEA between $80-120 \mathrm{~mm}$ and 120-210 mm TL P. argentata suggested ontogenetic niche shifts in this species, they did not inform us regarding the fundamental causes of habitat and dietary changes.

Meanwhile, SCA provides information concerning diet items for a species by optical resolution, and information on ontogenetic diet shifts, as well. Therefore, assuming that distinct SEA among the size-classified $P$. argentata is caused by diet shifts, $P$. argentata will have variable dietary items accompanying their body size. Unfortunately, resolution of our results involving SCA could not identify dietary items to species level due to large numbers of empty stomachs in the $60-80 \mathrm{~mm}$ TL class, and a high proportion of unidentifiable items (Table 2). Due to these issues, previous studies recommended large numbers of specimens for SCA to obtain more reliable information $[15,16]$. The number of samples for SCA in the present study (78 individuals) seems to be a relatively small number to obtain precise dietary information for P. argentata. Nevertheless, the large proportion of crustaceans identified in all sizes of P. argentata, as shown in our SCA results, is consistent with previous reports suggesting the importance of crustaceans as a major dietary component for this species by SCA [25] and SIA [38]. In addition, the contributions of Polychaeta as diet items for each size class of $P$. argentata were varied in a previous study [26]. Although size classification was slightly different in the present study, such previous reports support our findings in terms of the variable proportion of Polychaeta as a dietary resource among different size classes of $P$. argentata. Therefore, specific diet information was not involved in our SCA results; however, shifts in major dietary items among the size classes were certainly confirmed.

Furthermore, differences in diet composition between 80-120 mm and 120-210 mm TL of $P$. argentata were demonstrated by SCA and were well matched by our SEA results. Distinctively higher contributions of polychaeta as diet items in 80-120 mm TL group compared to $120-210 \mathrm{~mm}$ TL group seemed to result in separated $\delta$-space between these classes. 
As $\delta^{13} \mathrm{C}$ values in benthic fish are higher than those in pelagic organisms in general [39,40], the higher $\delta^{13} \mathrm{C}$ value in $\delta$-space of the $80-120 \mathrm{~mm}$ TL class than that in the $120-210 \mathrm{~mm}$ TL specimens, thus, reinforced our SCA results involving high benthic diet contributions in the 80-120 mm TL cohort. Meanwhile, crustacean remarkably contributes as diet item for 120-210 mm TL and also was important diet for 80-120 mm TL (approximately 40\%). The considerable contribution of this common diet for these two groups explains partial overlap in $\delta$-space between them. Therefore, our SCA results support that ontogenetic niche shifts in P. argentata were caused by dietary, rather than habitat, changes.

\section{Conclusions}

Understanding ontogenetic niche shifting is essential for management of fisheries, as it is one of the most representative survival strategies of organisms. The present study applied combined analyses of SIA and SCA to evaluate ontogenetic niche shift in a commercially important coastal fish, the Silver croaker P. argentata. Thus far, although combined analyses of SIA and SCA have been widely employed as powerful tools for tracing diet resources for marine consumers, this approach has not been used in ecological niche studies. The distinctive niche area between different fish size groups, as demonstrated by SIA, represents clear evidence of ontogenetic niche shifting. Moreover, our SCA results indicated that such an ontogenetic shift is strongly related to changes in dietary items concomitant with growth of $P$. argentata.

Consequently, the present study demonstrated the applicability of combined SIA and SCA analysis to obtain concrete information regarding ecological niches, and will help to further understand ecological strategies involving commercial marine fish.

Author Contributions: Conceptualization, B.C. and I.-S.K.; methodology, B.C. and I.-S.K.; software, W.-S.K.; validation, B.C. and M.-S.K.; formal analysis, M.-S.K.; investigation, W.-S.K.; resources, B.C. and C.W.J.; data curation, B.C.; writing-original draft preparation, B.C. and I.-S.K.; writing-review and editing, B.C., C.W.J., and I.-S.K.; visualization, B.C.; supervision, I.-S.K.; project administration, I.-S.K.; funding acquisition, I.-S.K. All authors have read and agreed to the published version of the manuscript.

Funding: This research was funded by the National Research Foundation of Korea, grant number NRF-2018-R1A6A1A-03024314 and by the Chonnam National University (grant number 2016-2692).

Institutional Review Board Statement: All experiments involving P. argentata in this study were carried out in accordance with the guidelines and regulations approved by the Institutional Animal Care and Use Committee of Chonnam National University.

Informed Consent Statement: Not applicable.

Data Availability Statement: The data presented in this study are available in "Application of combined analyses of stable isotopes and stomach contents for understanding ontogenetic niche shifts in Silver croaker (Pennahia argentata)".

Conflicts of Interest: The authors declare no conflict of interest.

\section{References}

1. Newsome, S.D.; Martinez del Rio, C.; Bearhop, S.; Phillips, D.L. A niche for isotopic ecology. Front. Ecol. Environ. 2007, 5, 429-436. [CrossRef]

2. DeNiro, M.J.; Epstein, S. Influence of diet on the distribution of carbon isotopes in animals. Geochim. Cosmochim. Acta 1978, 42, 495-506. [CrossRef]

3. Minagawa, M.; Wada, E. Stepwise enrichment of ${ }^{15} \mathrm{~N}$ along food chains: Further evidence and the relation between $\delta^{15} \mathrm{~N}$ and animal age. Geochim. Cosmochim. Acta 1984, 48, 1135-1140. [CrossRef]

4. Layman, C.A.; Quattrochi, J.P.; Peyer, C.M.; Allgeier, J.E. Niche width collapse in a resilient top predator following ecosystem fragmentation. Ecol. Lett. 2007, 10, 937-944. [CrossRef] [PubMed]

5. Jackson, A.L.; Inger, R.; Parnell, A.C.; Bearhop, S. Comparing isotopic niche widths among and within communities: SIBER-Stable Isotope Bayesian Ellipses in R. J. Anim. Ecol. 2011, 80, 595-602. [CrossRef] [PubMed] 
6. Yurkowski, D.J.; Ferguson, S.; Choy, E.S.; Loseto, L.L.; Brown, T.M.; Muir, D.C.G.; Semeniuk, C.A.D.; Fisk, A.T. Latitudinal variation in ecological opportunity and intraspecific competition indicates differences in niche variability and diet specialization of Arctic marine predators. Ecol. Evol. 2016, 6, 1666-1678. [CrossRef]

7. Shiffman, D.S.; Kaufman, L.; Heithaus, M.; Hammerschlag, N. Intraspecific differences in relative isotopic niche area and overlap of co-occurring sharks. Aquat. Ecol. 2019, 53, 233-250. [CrossRef]

8. Zhu, Y.; Newman, S.P.; Reid, W.D.K.; Polunin, N.V.C. Fish stable isotope community structure of a Bahamian coral reef. Mar. Biol. 2019, 166, 160. [CrossRef]

9. Herzka, S.Z. Assessing connectivity of estuarine fishes based on stable isotope ratio analysis. Estuar. Coast. Shelf Sci. 2005, 64, 58-69. [CrossRef]

10. Nakamura, Y.; Horinouchi, M.; Shibuno, T.; Tanaka, Y.; Miyajima, T.; Koike, I.; Kurokura, H.; Sano, M. Evidence of ontogenetic migration from mangroves to coral reefs by black-tail snapper Lutjanus fulvus: Stable isotope approach. Mar. Ecol. Prog. Ser. 2008, 355, 257-266. [CrossRef]

11. Choi, B.; Lee, C.; Takizawa, Y.; Chikaraishi, Y.; Oh, H.J.; Chang, K.H.; Jang, M.H.; Kim, H.W.; Lee, K.L.; Shin, K.H. Trophic response to ecological conditions of habitats: Evidence from trophic variability of freshwater fish. Ecol. Evol. 2020, 10, 7250-7260. [CrossRef]

12. Xing, D.; Choi, B.; Takizawa, Y.; Fan, R.; Sugaya, S.; Tsuchiya, M.; Ohkouchi, N.; Chikaraishi, Y. Trophic hierarchy of coastal marine fish communities viewed via compound-specific isotope analysis of amino acids. Mar. Ecol. Prog. Ser. 2020, 652, 137-144. [CrossRef]

13. Churchill, D.A.; Heithaus, M.R.; Vaudo, J.J.; Grubbs, R.D.; Gastrich, K.; Castro, J.I. Trophic interactions of common elasmobranchs in deep-sea communities of the Gulf of Mexico revealed through stable isotope and stomach content analysis. Deep-Sea Res. Part II Top. Stud. Oceanogr. 2015, 115, 92-102. [CrossRef]

14. Baker, R.; Buckland, A.; Sheaves, R. Fish gut content analysis: Robust measures of diet composition. Fish Fish. 2014, 15, 170-177. [CrossRef]

15. Davis, A.M.; Blanchette, M.L.; Pusey, B.J.; Jardine, T.D.; Pearson, R.G. Gut content and stable isotope analyses provide complementary understanding of ontogenetic dietary shifts and trophic relationships among fishes in a tropical river. Freshw. Biol. 2012, 57, 2156-2172. [CrossRef]

16. McClain-Counts, J.P.; Demopoulos, A.W.J.; Ross, S.W. Trophic structure of mesopelagic fishes in the Gulf of Mexico revealed by gut content and stable isotope analyses. Mar. Ecol. 2017, 38, e12449. [CrossRef]

17. Cummings, D.O.; Booth, D.J.; Lee, R.W.; Simpson, S.J.; Pile, A.J. Ontogenetic diet shifts in the reef fish Pseudanthias rubrizonatus from isolated populations on the North-West Shelf of Australia. Mar. Ecol. Prog. Ser. 2010, 419, 211-222. [CrossRef]

18. Yamada, U. Sciaenidae. In Fishes of Japan with Pictorial Keys to the Species, 2nd ed.; Nakado, T., Ed.; Tokai University Press: Tokyo, Japan, 2000; pp. 867-870.

19. Yamaguch, A.; Kume, G.; Higuchi, T.; Takita, T. Geographic variation in the growth of white croaker Pennahia argentata, off the coast of northwest Kyushu, Japan. Environ. Biol. Fishes 2004, 71, 179-188. [CrossRef]

20. Cheng, T.; Xu, T.; Jin, X.; Shi, G.; Wang, R. The complete mitochondrial genome of silver croaker Argyrosomus argentatus (Perciforems; Sciaenidae): Genome characterization and phylogenetic consideration. Mol. Biol. 2012, 46, 200-209. [CrossRef]

21. Koh, E.H.; An, Y.S.; Baeck, G.W.; Jang, C.S. Feeding habits of white croaker, Pennahia argentata in the coastal waters off Sejon island, Korea. J. Kor. Soc. Fish. Tech. 2014, 50, 139-146. [CrossRef]

22. Post, D.M. Individual variation in the timing of ontogenetic niche shift in largemouth bass. Ecology 2003, 84, 1298-1310. [CrossRef]

23. Kim, D.K.; Jo, H.; Han, I.; Kwak, I.S. Explicit Characterization of Spatial Heterogeneity Based on Water Quality, Sediment Contamination, and Ichthyofauna in a Riverine-to-Coastal Zone. Int. J. Environ. Res. Public Health 2019, 16, 409. [CrossRef]

24. Biela, V.R.; Newsome, S.D.; Bodkin, J.L.; Kruse, G.H.; Zimmerman, C.E. Widespread kelp-derived carbon in pelagic and benthic nearshore fishes suggested by stable isotope analysis. Estuar. Coast. Shelf Sci. 2016, 181, 364-374. [CrossRef]

25. Huh, S.H.; Choi, H.C.; Park, J.M. Feeding relationship between co-occurring silver croaker (Pennahia argentata) and Japanese sillago (Sillago japonica) in the Nakdong River estuary, Korea. Korean J. Ichthyol. 2018, 30, 224-231. [CrossRef]

26. Park, J.M.; Kwak, S.N.; Lee, W.C. Dietary study using set-nets produces bias in prey choice of fish: A case of three coastal fishes inhabiting southern Korean waters. J. Sea Res. 2020, 157, 101846. [CrossRef]

27. Werner, E.E.; Gilliam, J.F. The ontogenetic niche and species interactions in size-structured populations. Ann. Rev. Ecol. Syst. 1984, 15, 393-425. [CrossRef]

28. Hjelm, J.; Persson, L.; Christensen, B. Growth, morphological variation and ontogenetic niche shifts in perch (Perca fluviatilis) in relation to resource availability. Oecologia 2000, 122, 190-199. [CrossRef] [PubMed]

29. Ju, P.L.; Yang, L.; Lu, Z.B.; Yang, S.Y.; Du, J.G.; Zhong, H.Q.; Chen, J.; Xiao, J.M.; Chen, M.R.; Zhang, C.Y. Age, growth, mortality and population structure of silver croaker Pennahia argentata. J. Appl. Ichthyol. 2016, 32, 652-660. [CrossRef]

30. Werner, E.E.; Mittelbach, G.G.; Hall, D.J.; Gilliam, J.F. Experimental tests of optimal habitat use in fish: The role of relative habitat profitability. Ecology 1983, 64, 1525-1539. [CrossRef]

31. Kernaléguen, L.; Arnould, J.P.; Guinet, C.; Cazelles, B.; Richard, P.; Cherel, Y. Early-life sexual segregation: Ontogeny of isotopic niche differentiation in the Antarctic fur seal. Sci. Rep. 2016, 6, 33211. [CrossRef]

32. Zhu, G.; Deng, B.; Zhang, H.; Yang, Q. Ontogenetic and temporal diet variation in adult Antarctic krill Euphausia superba at South Georgia during austral winter revealed by stable isotope analysis. Fish. Res. 2019, 215, 1-8. [CrossRef] 
33. Krumsick, K.J.; Fisher, J.A.D. Spatial and ontogenetic variation in isotopic niche among recovering fish communities revealed by Bayesian modeling. PLoS ONE 2019, 14, e0215747. [CrossRef]

34. Sherwood, G.D.; Rose, G.A. Stable isotope analysis of some representative fish and invertebrates of the Newfoundland and Labrador continental shelf food web. Estuar. Coast. Shelf Sci. 2005, 63, 537-549. [CrossRef]

35. Hansen, J.H.; Hedeholm, R.B.; Sünksen, K.; Christensen, J.T.; Grønkjær, P. Spatial variability of carbon $\left(\delta^{13} C\right)$ and nitrogen $\left(\delta^{15} N\right)$ stable isotope ratios in an Arctic marine food web. Mar. Ecol. Prog. Ser. 2012, 467, 47-59. [CrossRef]

36. Carlisle, A.B.; Goldman, K.J.; Litvin, S.Y.; Madigan, D.J.; Bigman, J.S.; Swithenbank, A.M.; Kline, T.C., Jr.; Block, B.A. Stable isotope analysis of vertebrae reveals ontogenetic changes in habitat in an endothermic pelagic shark. Proc. R. Soc. B 2015, 282, 20141446. [CrossRef]

37. Snover, M.L.; Hohn, A.A.; Crowder, L.B.; Macko, S.A. Combining stable isotopes and skeletal growth marks to detect habitat shifts in juvenile loggerhead sea turtles Caretta caretta. Endanger. Species Res. 2010, 13, 25-31. [CrossRef]

38. Tue, N.T.; Hamaoka, H.; Quy, T.D.; Nhuan, M.T.; Sogabe, A.; Nam, N.T.; Omori, K. Dual isotope study of food sources of a fish assemblage in the Red River mangrove ecosystem, Vietnam. Hydrobiologia 2013, 733, 71-83. [CrossRef]

39. Corbisier, T.N.; Petti, M.A.V.; Skowronski, R.S.P.; Brito, T.A.S. Trophic relationships in the nearshore zone of Martel Inlet (King George Island, Antarctica): $\delta^{13} \mathrm{C}$ stable-isotope analysis. Polar Biol. 2004, 27, 75-82. [CrossRef]

40. An, Y.; Hong, S.; Kim, Y.; Kim, M.; Choi, B.; Won, E.J.; Shin, K.H. Trophic transfer of persistent toxic substances through a coastal food web in Ulsan Bay, South Korea: Application of compound-specific isotope analysis of nitrogen in amino acids. Environ. Pollut. 2020, 266, 115160. [CrossRef] 